\title{
Comparison of the suitability of three pest leafminers (Diptera: Agromyzidae) as hosts for the parasitoid Dacnusa sibirica (Hymenoptera: Braconidae)
}

\author{
Yoshinisa ABE ${ }^{1}$, Tomohiko TAKEUCHI ${ }^{1}$, Susumu TOKUMARU ${ }^{2}$ and Jun KAMATA ${ }^{3}$ \\ ${ }^{1}$ Laboratory of Applied Entomology, Graduate School of Agriculture, Kyoto Prefectural University, Kyoto 606-8522, Japan; \\ e-mail: y_abe@kpu.ac.jp \\ ${ }^{2}$ Kyoto Prefectural Agricultural Research Institute, Amarube, Kameoka, Kyoto 621-0806, Japan \\ ${ }^{3}$ Arysta LifeScience Co. Ltd., 8-1, Akashi-cho, Chuo, Tokyo 104-6591, Japan
}

Key words. Biological control, Agromyzidae, Liriomyza, Braconidae, Dacnusa, development, survival, sex ratio, body size

\begin{abstract}
The suitability of Liriomyza sativae Blanchard, L. trifolii (Burgess) and L. bryoniae (Kaltenbach) as hosts of the solitary larval-pupal parasitoid Dacnusa sibirica Telenga was studied. This parasitoid is used as a biological control agent against $L$. trifolii and $L$. bryoniae. The parasitoid laid eggs in L. sativae, but no adult parasitoids emerged from the puparia. In contrast, $D$. sibirica adults emerged from the puparia of $L$. trifolii and L. bryoniae, and there was no significant difference in emergence rate, female developmental time, or sex ratio when parasitizing these two host species. The parasitoid adults that emerged from the $L$. bryoniae puparia were significantly larger than those from $L$. trifolii puparia. In conclusion, D. sibirica, a useful biological control agent of $L$. trifolii and L. bryoniae, cannot control L. sativae.
\end{abstract}

\section{INTRODUCTION}

Dacnusa sibirica Telenga (Hymenoptera: Braconidae) is a solitary larval-pupal parasitoid that attacks Liriomyza (Diptera: Agromyzidae) pests (Minkenberg \& van Lenteren, 1986). It is used as a biological control agent for the serpentine leafminer, L. trifolii (Burgess), tomato leafminer, L. bryoniae (Kaltenbach) and pea leafminer, L. huidobrensis (Blanchard) in Europe (Malais \& Ravensberg, 1991), and is effective against L. trifolii in Japan (Ozawa et al., 2001).

Similar to L. trifolii and L. huidobrensis, the vegetable leafminer, L. sativae Blanchard, is indigenous to the New World and causes serious damage to vegetables and ornamentals (Spencer, 1973). This leafminer extended its geographical range to Africa and Asia in the 1990s (Iwasaki et al., 2000) and coexists with $L$. trifolii and L. bryoniae on tomato plants in Japan (Abe \& Kawahara, 2001). The spread of $L$. sativae is considered to have been caused by the world-wide trade of crops. To determine whether $D$. sibirica can be used as a biological control agent against $L$. sativae, the host suitability of $L$. sativae was compared with that of L. trifolii and L. bryoniae.

\section{MATERIAL AND METHODS}

\section{Insects and plants}

All insects were maintained and tested at $25^{\circ} \mathrm{C}$ under a $15 \mathrm{~L}$ : 9D photoperiod. Laboratory cultures of Japanese populations of L. sativae, L. trifolii, and L. bryoniae were established from larvae collected in Joyo (Kyoto Prefecture), Itoman (Okinawa Prefecture) and Kyoto (Kyoto Prefecture), respectively. Kidney bean, Phaseolus vulgaris L., was used as a host plant for leafminer colony maintenance and experiments (for rearing details see Abe, 2001). A laboratory culture of $D$. sibirica on L. trifolii was established from individuals that were reared at Arysta LifeScience Co., Ltd (Tokyo).

\section{Emergence rate, developmental time and sex ratio}

After emergence, female wasps of $D$. sibirica were placed with one male in a glass tube $(8 \mathrm{~mm}$ diameter, $4 \mathrm{~cm}$ high) for mating. One day later, they were used in the experiments. The oviposition rate of $D$. sibirica is highest on the second day after emergence at $25^{\circ} \mathrm{C}$ (Minkenberg, 1990).

Dacnusa sibirica females prefer first and second instar larvae of Liriomyza spp. for oviposition (Malais \& Ravensberg, 1991). Therefore, $P$. vulgaris plants, with two true leaves, was infested with 2-day-old (first instar) larvae of each Liriomyza species as described in Abe (2001). The base of the stem of each plant was immersed in water in a $10-\mathrm{ml}$ glass vial; the vial was attached to the inside of the bottom of a cylindrical glass tube $(6.4 \mathrm{~cm}$ diameter, $22 \mathrm{~cm}$ high). The top of the tube was covered with organdy and the bottom with Kimwipe ${ }^{\circledR}$. Undiluted honey was streaked on the inside of the tube as a food source for the wasps. Just after transferring a plant into a tube, one mated female adult of $D$. sibirica was released in the tube and allowed to oviposit in the Liriomyza larvae for $24 \mathrm{~h}$ before removal. Ten wasps were used for each Liriomyza species. There was no significant difference in the mean number of host larvae per replicate among the three species (Table 1, ANOVA, $\mathrm{F}=0.540$, d.f. $=2, \mathrm{P}>$ 0.05). After removal of the wasps, the immature Liriomyza were reared and the emergence of D. sibirica wasps was recorded. The adult wasps that emerged were sexed and the lengths of the hind tibia (as indices of body size) of 15 randomly chosen wasps of each sex of each species were measured to the nearest $6.7 \mu \mathrm{m}$ under a binocular microscope. After adult emergence,

TABLE 1. Effects of host species on emergence rate and sex ratio of Dacnusa sibirica. Mean \pm SE. Means with the same letter were not significantly different from each other in the same column $(\mathrm{n}=10)$.

\begin{tabular}{lccc}
\hline Host species & $\begin{array}{c}\text { Number of } \\
\text { host larvae } \\
\text { exposed }\end{array}$ & $\begin{array}{c}\text { Emergence rate of } \\
\text { D. sibirica }(\operatorname{arcsine} \\
\text { transformed) }\end{array}$ & $\begin{array}{c}\text { Sex ratio of } D . \\
\text { sibirica } \text { (arcsine } \\
\text { transformed) }\end{array}$ \\
\hline L. sativae & $30.8 \pm 3.8 \mathrm{a}$ & $0(0) \mathrm{a}$ & - \\
L. trifolii & $33.9 \pm 3.6 \mathrm{a}$ & $0.50 \pm 0.09$ & $0.49 \pm 0.10$ \\
& & $(45.1 \pm 5.4) \mathrm{b}$ & $(44.4 \pm 7.7) \mathrm{a}$ \\
L. bryoniae & $28.7 \pm 3.2 \mathrm{a}$ & $0.66 \pm 0.05$ & $0.50 \pm 0.06$ \\
& & $(55.1 \pm 2.9) \mathrm{b}$ & $(43.3 \pm 3.8) \mathrm{a}$ \\
\hline
\end{tabular}


TABLE 2. Effects of exposure to Dacnusa sibirica on pupal mortality of Liriomyza sativae. Mean $\pm \mathrm{SE}$. Means were not significantly different from each other in the same column $(\mathrm{n}=$ $10)$.

\begin{tabular}{lcc}
\hline & $\begin{array}{c}\text { Number of } \\
\text { puparia }\end{array}$ & $\begin{array}{c}\text { Pupal mortality of L. sativae in puparia } \\
\text { without exit holes (arcsine transformed) }\end{array}$ \\
\hline Treatment & $30.8 \pm 3.8$ & $\begin{array}{c}0.26 \pm 0.04 \\
(30.3 \pm 2.7)\end{array}$ \\
\hline Control & $31.3 \pm 3.5$ & $\begin{array}{l}0.19 \pm 0.04 \\
(25.2 \pm 2.4)\end{array}$ \\
\hline
\end{tabular}

host puparia with no exit holes were dissected under a binocular microscope to record mortality of Liriomyza species and larval, pupal, or adult mortality of $D$. sibirica. As a control, $10 P$. vulgaris plants infested with $L$. sativae were prepared and reared without a wasp. After adult emergence, mortality of $L$. sativae was recorded.

\section{Parasitization of $L$. sativae}

As in the previous experiment, 2-day-old larvae of $L$. sativae were exposed to a mated female of D. sibirica for $24 \mathrm{~h}$ in a cylindrical glass tube. The mean $( \pm \mathrm{SE})$ number of $L$. sativae larvae per wasp was $43.6 \pm 4.6(n=10)$. After removal of the wasp from the tube, the L. sativae larvae were reared for two days. Then each $L$. sativae larva was transferred into a drop of Ringer's solution on a glass slide and dissected with two minute pins under a microscope. The number and developmental stage of $D$. sibirica found in the L. sativae larvae were recorded.

\section{Data analysis}

Arcsine transformed data of emergence rate and sex ratio in D. sibirica were analyzed with Scheffé's multiple comparison test (Scheffé, 1953) and one-way ANOVA, respectively. Effects of exposure to D. sibirica on pupal mortality of $L$. sativae were also analyzed with one-way ANOVA after arcsine transformation. Effects of host species on body size and developmental time of $D$. sibirica were analyzed using Scheffé's multiple comparison test. The significance level for all statistical tests was set at $\mathrm{P}=0.05$.

\section{RESULTS}

\section{Emergence rate, developmental time and sex ratio}

Except for seven L. bryoniae larvae, all Liriomyza larvae formed puparia. No dead larvae, pupae, or adults of $D$. sibirica were found in host puparia without exit holes. These puparia contained only dead host pupae. Adults of $D$. sibirica did not emerge from the L. sativae puparia (Table 1). The pupal mortality of $L$. sativae did not differ significantly between treatment and control (Table 2, ANOVA, $\mathrm{F}=1.925$, d.f. $=1$, P $>0.05$ ). In contrast, adults of $D$. sibirica emerged from the $L$. trifolii and $L$. bryoniae puparia (Table 1). Neither the emergence rate (number of adult wasps that emerged / host puparium) of D. sibirica (Table 1, ANOVA, $\mathrm{F}=2.653$, d.f. $=1, \mathrm{P}>0.05$ ) nor the sex

TABLE 3. Effects of host species on hind tibial length of Dacnusa sibirica. Mean \pm SE. Means with the same letter were not significantly different from each other $(\mathrm{n}=15)$.

\begin{tabular}{lcc}
\hline Host species & Sex & Hind tibial length $(\mathrm{mm})$ \\
\hline L. trifolii & Male & $0.494 \pm 0.010 \mathrm{a}$ \\
& Female & $0.508 \pm 0.008 \mathrm{a}$ \\
\hline \multirow{2}{*}{ L. bryoniae } & Male & $0.587 \pm 0.009 \mathrm{~b}$ \\
& Female & $0.593 \pm 0.013 \mathrm{~b}$ \\
\hline
\end{tabular}

Table 4. Effects of host species on developmental time of Dacnusa sibirica. Mean \pm SE. Means with the same letter were not significantly different from each other.

\begin{tabular}{lccc}
\hline Host species & Sex & $\begin{array}{c}\text { Number } \\
\text { of individuals }\end{array}$ & $\begin{array}{c}\text { Total developmental time } \\
\text { from oviposition to adult } \\
\text { emergence (day) }\end{array}$ \\
\hline L. trifolii & Male & 86 & $15.6 \pm 0.1 \mathrm{a}$ \\
& Female & 67 & $17.0 \pm 0.1 \mathrm{c}$ \\
\hline \multirow{2}{*}{ L. bryoniae } & Male & 99 & $16.3 \pm 0.1 \mathrm{~b}$ \\
& Female & 89 & $16.9 \pm 0.1 \mathrm{c}$ \\
\hline
\end{tabular}

ratio (Table 1, ANOVA, $\mathrm{F}=0.009$, d.f. $=1, \mathrm{P}>0.05$ ) differed significantly between $L$. trifolii and $L$. bryoniae. Hind tibial lengths of $D$. sibirica that emerged from L. bryoniae puparia were significantly longer than those from $L$. trifolii puparia (Table 3, Scheffe's multiple comparison test, $\mathrm{P}<0.05$ ). Table 4 shows total developmental times, from oviposition to adult emergence of both sexes of D. sibirica raised on L. trifolii and $L$. bryoniae. The total developmental time of male $D$. sibirica was significantly shorter than that of female $D$. sibirica in each host species (Scheffe's multiple comparison test, $\mathrm{P}<0.05$ ). The total developmental time of male $D$. sibirica that emerged from L. trifolii puparia was significantly shorter (albeit less than one day) than that from L. bryoniae puparia (Scheffe's multiple comparison test, $\mathrm{P}<0.05)$. However, no significant difference was found in total developmental time of female D. sibirica between the two host species (Scheffe's multiple comparison test, $\mathrm{P}>0.05$ )

\section{Parasitization of $L$. sativae}

Eggs of D. sibirica were found in L. sativae larvae in each replicate, and first instar larvae of the wasp were found in six replicates. The mean $( \pm \mathrm{SE})$ parasitization rate and egg hatchability for the ten replicates were $0.61 \pm 0.08$ and $0.30 \pm 0.10$, respectively. Superparasitism occurred in three replicates. The rates of superparasitism (number of hosts containing more than one $D$. sibirica / number of hosts containing any $D$. sibirica) were $0.06,0.17$, and 0.17 .

\section{DISCUSSION}

Our results reveal that $D$. sibirica cannot complete its development in L. sativae. Females of D. sibirica oviposited in $L$. sativae larvae and some of these eggs hatched. However, no adult wasps emerged from the puparia. Moreover, parasitization by $D$. sibirica did not significantly influence the mortality of $L$. sativae pupae. Thus, L. sativae is not a suitable host for $D$. sibirica. Further study is required to clarify how $L$. sativae kills the immature stages of $D$. sibirica.

In contrast, $L$. trifolii and $L$. bryoniae are equally suitable as hosts for $D$. sibirica, because $D$. sibirica adults emerged from the puparia of both species, with no significant difference in emergence rate, female developmental time, or sex ratio between the two host species. Adult wasps that emerged from $L$. bryoniae puparia were significantly larger than those from $L$. trifolii puparia. Host pupae can be regarded as fixed host resource available for the development of $D$. sibirica offspring. The pupa of $L$. bryoniae is larger than that of L. trifolii (Abe, in press.). Thus, the difference in body size of $D$. sibirica adults may be caused by the difference in pupal size of the two host species.

Generally, large female parasitoids have higher fitness than small females (King, 1987; Visser, 1994). Under field conditions, such a relationship between female size and fitness has been demonstrated in some parasitoids (Visser, 1994; Kazmer \& 
Luck, 1995; West et al., 1996; Bennett \& Hoffmann, 1998; Ellers et al., 1998). Thus, in order to estimate the fitness of parasitoids, size has been investigated in a number of studies of biological control and evolutionary ecology (Roitberg et al., 2001). Since size and fecundity in $D$. sibirica females are positively related (Croft \& Copland, 1993), L. bryoniae would be a more suitable host than L. trifolii for D. sibirica.

Among the three Liriomyza species studied, L. sativae and $L$. trifolii are more closely related to one another than they are to L. bryoniae, judging from their external morphology (Spencer, 1973). This phylogenetic relationship is supported by mitochondrial sequence data (Miura et al., 2004). Moreover, the close relationship between $L$. sativae and $L$. trifolii is indicated by the production of hybrids under laboratory conditions (Tokumaru \& Abe, in press). The present results show that, unlike L. trifolii and L. bryoniae, L. sativae is not a good host for D. sibirica. Thus, phylogenetic relationship and suitability for parasitoid survival and development are not congruent among the host species used in this study

ACKNOWLEDGEMENTS. We would like to thank H. Takada and Y. Yoshiyasu for their suggestions.

\section{REFERENCES}

ABE Y. 2001: Egg-pupal and larval-pupal parasitism in the parasitoid Gronotoma micromorpha (Hymenoptera: Eucoilidae). Appl. Entomol. Zool. 36: 479-482.

AвE Y. 2006: Exploitation of the serpentine leafminer Liriomyza trifolii and tomato leafminer L. bryoniae (Diptera: Agromyzidae) by the parasitoid Gronotoma micromorpha (Hymenoptera: Eucoilidae). Eur. J. Entomol. 103: in press.

Abe Y. \& Kawahara T. 2001: Coexistence of the vegetable leafminer, Liriomyza sativae (Diptera: Agromyzidae), with L. trifolii and L. bryoniae on commercially grown tomato plants. Appl. Entomol. Zool. 36: 277-281.

Bennett D.M. \& Hoffmann A.A. 1998: Effects of size and fluctuating asymmetry on field fitness of the parasitoid Trichogramma carverae (Hymenoptera: Trichogrammatidae). $J$. Anim. Ecol. 67: 580-591.

Croft P. \& Copland M.J.W. 1993: Size and fecundity in Dacnusa sibirica Telenga. IOBC WPRS Bull. 16: 53-56.

Ellers J., van Alphen J.J.M. \& Sevenster J.G. 1998: A field study of size-fitness relationships in the parasitoid Asobara tabida. J. Anim. Ecol. 67: 318-324.

Iwasaki A., Kasugai K., Iwaizumi R. \& Sasakawa M. 2000: A newly recorded pest, Liriomyza sativae Blanchard in Japan. Shokubutsu-boeki 54: 142-147 (in Japanese).
KAZMER D.J. \& Luck R.F. 1995: Field tests of the size-fitness hypothesis in the egg parasitoid Trichogramma pretiosum. Ecology 76: 412-425.

KING B.H. 1987: Offspring sex ratios in parasitoid wasps. Quart. Rev. Biol. 62: 367-396.

Malais M. \& Ravensberg W.J. 1991: The Biology of Glass House Pests and Their Natural Enemies, Knowing and Recognizing. (Yano E. et al. transl., 1995). Nosan-gyoson-bunkakyokai, Tokyo, 116 pp. (in Japanese).

MinKENBERG O.P.J.M. 1990: Reproduction of Dacnusa sibirica (Hymenoptera: Braconidae), an endoparasitoid of leafminer Liriomyza bryoniae (Diptera: Agromyzidae) on tomatoes, at constant temperatures. Envir. Entomol. 19: 625-629.

MinKenBerg O.P.J.M. \& van Lenteren J.C. 1986: The leafminers Liriomyza bryoniae and L. trifolii (Diptera: Agromyzidae), their parasites and host plants: a review. Agric. Univ. Wageningen Papers 86(2): 1-50.

Miura K., Tagami Y., Ohtaishi M. \& Iwasaki A. 2004: Application of molecular techniques to distinguish Liriomyza trifolii from L. sativae (Diptera: Agromyzidae) on tomato cultivation in Japan. J. Econ. Entomol. 97: 964-969.

Ozawa A., Saito T. \& Ota M. 2001: Biological control of the American serpentine leafminer, Liriomyza trifolii (Burgess), on tomato in greenhouses by parasitoids. II. Evaluation of biological control by Diglyphus isaea (Walker) and Dacnusa sibirica Telenga in commercial greenhouses. Jpn. J. Appl. Entomol. Zool. 45: 61-74 (in Japanese, English abstr.).

Roitberg B.D., Borvin G. \& Vet L.E.M. 2001: Fitness, parasitoids, and biological control: an opinion. Can. Entomol. 133: 429-438.

SCHEFFÉ H. 1953: A method of judging all contrasts in the analysis of variance. Biometrika 40: 87-104.

SPENCER K.A. 1973: Agromyzidae (Diptera) of Economic Importance. Dr. W. Junk, The Hague, 418 pp.

TOKUMARU S. \& ABE Y. (in press): Interspecific hybridization between Liriomyza sativae Blanchard and L. trifolii (Burgess) (Diptera: Agromyzidae). Appl. Entomol. Zool.

VISSER M.E. 1994: The importance of being large: the relationship between size and fitness in females of the parasitoid Aphaereta minuta (Hymenoptera: Braconidae). J. Anim. Ecol. 63: 963-978.

West S.A., Flanagan K.W. \& Godfray H.C.J. 1996: The relationship between parasitoid size and fitness in the field, a study of Achrysocharoides zwoelferi (Hymenoptera: Eulophidae). J. Anim. Ecol. 65: 631-639.

Received October 8, 2004; revised and accepted April 11, 2005 